\title{
Relations between Dysmorphic Tendency and Body Satisfaction in Female Japanese Youth
}

\author{
Minako OHMURA \\ Department of Psychology, University of Social Welfare, Tokyo 170-0013, Japan
}

Received: January 20, 2015 / Accepted: February 8, 2015 / Published: February 28, 2015.

\begin{abstract}
This study examined the relationship of dysmorphic tendency and satisfaction with each body part (body shape, eyes, nose and mouth, skin, and hair) among female Japanese youth. Participants were 186 female university students. The study found that satisfaction with body parts and dysmorphic tendency were related. However, differences were found in dysmorphic tendency based on feelings about each body part.
\end{abstract}

Key words: Dysmorphic tendency, body satisfaction, female youth.

\section{Introduction}

In recent years, there has been an increase in the number of adolescents with an obsession about their physical appearance. The Cabinet Office of Japan conducted the Eighth World Youth Survey in 2009 [1]. The results showed that in Japanese, men and women aged from 18 to 24 years, worried about one's physical appearance had increased from $6.3 \%$ in 2003 to $11.1 \%$ in 2008 . When these figures are viewed by gender, $7.2 \%$ of men worried about their appearance and $14.9 \%$ of women did so.

Dysmorphic phobia has attracted attention in clinical psychology and psychiatry. Dysmorphic phobia is listed as Body Dysmorphic Disorder ${ }^{1}$ under Obsessive-Compulsive and Related Disorders in the DSM-5 (APA, 2013) [2]. The prevalence of dysmorphic phobia in the general population is estimated to be $0.7-2.3 \%$ [3, 4]. Individuals with dysmorphic phobia are not satisfied with particular body parts such as skin and hair [5].

It has been suggested that there is a connection between dysmorphic phobia and an obsession with

\footnotetext{
Corresponding author: Minako OHMURA, Ph.D., research field: clinical psychology. E-mail: popyblancpoponoir@gmail.com.
}

appearance in healthy individuals as well. For example, Tanaka and Tayama [6] have pointed out that in both a clinical group of dysmorphic phobia patients and a non-clinical group, feelings of concern about one's physical appearance are similar and that this feature is continuous. Nabeta [7] and Cansever, Uzun, Dönmez, and Özşahin [8] have also reported that there are healthy university students who meet the diagnostic criteria of dysmorphic phobia. Their results also suggest a connection between dysmorphic phobia and obsession with one's appearance in healthy individuals.

Ohmura, Kojima, Nakata and Sawamiya [9] define dysmorphobia as "The tendency toward a strong obsession with the appearance of self, which is a strong interest toward appearance in the whole body or in the parts of the body". Ohmura et al. [9] conducted a study with 439 female undergraduates and developed the Dysmorphobia Tendency Scale for female youth. This scale consists of five items on "Apprehension about others' evaluation of one's appearance" and four on "Obsessive concentration on appearance".

Appearance is important to adolescents. Many of them have a tendency to feel dissatisfied with their 
bodies. Eda [10] conducted a survey of college women and found that more than $80 \%$ of them judged their figures to be "somewhat fat" or "fat", in spite of having a normal body weight. The result will be the possibility of seeing the manifestation of dissatisfaction with one's own body. Dissatisfaction with ones' body is usually accompanied with feelings of dissatisfaction with particular body parts as well as with the whole body in general. Ishihara and Osawa [11] revealed feelings of dissatisfaction in adolescent girls who felt they had swollen feet, large waistlines, or flabby arms. Ohmura et al. [12] reported that female adolescents were often not satisfied with their facial features and body shape.

Phillips et al. [5] discussed individuals with dysmorphic phobia who are not satisfied with specific body parts and Ohmura et al. [12] focused on females who are not satisfied with specific body parts. In the present study, the relationship between dysmorphic tendency and satisfaction with each body part in female adolescents was examined.

\section{Methods}

\subsection{Participants}

The survey was conducted at two points in time. The first survey was conducted in July-October 2013 with 186 female university students aged 18 to 26 years (M $=21.98, \mathrm{SD}=9.71)$ at three universities and one professional school located in the suburbs of Tokyo, Japan. The second was conducted in July 2014 with 156 female university students aged 18 to 29 years (M $=20.06, \mathrm{SD}=3.21)$ at the same institutions.

\subsection{Procedures}

The participants were recruited from psychology classes. The lecturers were contacted for permission to collect data from their students, and the students were told that they were not obligated to participate. The students were also told that if they did wish to participate, their responses would remain anonymous and confidential and that their participation would not influence their grades or their interactions with the lecturer in any way. At the end of the class period, the researchers conducted a short debriefing.

\subsection{Measurement}

\subsubsection{Dysmorphobia Tendency Scale (9 items)}

To assess the participants' dysmorphobia levels, the Dysmorphobia Tendency Scale developed by Ohmura et al. [13] was used, which consists of five items on Apprehension about others' evaluation of one's appearance and four on Obsessive concentration on appearance.

Students responded to the questions regarding degree of self-esteem using a five-point Likert scale (5, True, to 1, False).

2.3.2 Questions on body Satisfaction (32 items)

The survey used 26 questions ${ }^{2}$ from the Body Cathexis Scale [14] to measure respondents' satisfaction with their bodies. The researcher added six questions about hair style, hair quality, depth of eyebrows, entire face, makeup, and no makeup. ${ }^{3}$ Students responded using a five-point Likert scale (5, very satisfied, to 1 not satisfied) regarding their degree of satisfaction with each body part. Omura et al. (submitted) [13] conducted a factor analysis and classified the 32 items into 5 categories: Body shape: 9 items (obesity degree, waist thickness, arm thickness, proportions, form of hip, leg length, leg shape, finger length, shoulder width, neck thickness); Eyes: 3 items (eye size, eye shape, eyelash length); Nose and Mouth: 4 items (mouth size, lip thickness, nose shape, nose height); Skin: 5 items (skin luster, skin texture, no makeup, entire face, complexion, use of makeup), and Hair: 3 items (hair color, hair style, hair quality).

\section{Results}

The data of 288 female university students $(\mathrm{M}=$ $19.55, \mathrm{SD}=1.45$ ) were analyzed; no deficiencies in their responses were found. The respondents were then divided into two groups. Group 1 consisted of 150 students from the first survey, and Group 2 consisted of 
138 students from the second survey.

\section{Correlation Analysis}

A correlation analysis was performed to examine the relationship between satisfaction with the five body parts and dysmorphobia tendency (Table 1). The relationship between dysmorphobia tendency and satisfaction with specific body parts (body shape, eyes, nose and mouth, skin, and hair) was significantly positive $(r=.18, p<.01 ; r=.13, p<.05 ; r$ $=.18, p<.01 ; r=.21, p<.01 ; r=.12, p<.05$ respectively).

The relationships between Apprehension about others' evaluation of one's appearance and Satisfaction with body shape, skin, and nose and mouth were significantly positive $(r=.16, p<.01 ; r=.18, p$ $<.01 ; r=.20, p<.01$ respectively). No relationship was found between Apprehension about others' evaluation of one's appearanceand Satisfaction with eyes or hair.

The relationships between Obsessive concentration on appearance and Satisfaction with body shape and nose and mouth were significantly positive $(r=.16$, $p<.01 ; r=.16, p<.01$ respectively). No relationship was found between Obsessive concentration on appearance and Satisfaction with eyes, skin or hair.

\section{Discussion}

This study examined the relationship of dysmorphic tendency and satisfaction with each body part (body shape, eyes, nose and mouth, skin and hair) in female adolescents. A positive relationship was found between satisfaction with specific body parts and dysmorphic tendency. However, there was a difference this relationship depending on body part.

The difference of the hypostatic factor, is a skin. "Skin" was connected with Apprehension about others' evaluation of one's appearance. In contrast, there lationship between Obsessive concentration on appearance and feelings about body parts was not observed. Therefore, individuals who worried about being evaluated by others revealed that they felt most dissatisfied with their skin. Ohmura et al. (submitted) [13] showed that only Satisfaction with Skin has been shown to affect shyness and self-esteem. These results support the assertion that skin is an important part of the body for Japanese women and that it is likely directly connected to their self-concept.

The other four body parts were common hypostatic factors. Body shape, nose and mouth were related to apprehension about others' evaluation of one's appearance and Obsessive concentration on appearance. However, hair and eyes showed no relationship between these factors. In addition, Ohmura et al. [12] showed that female adolescents perceived body shape, nose and mouth as being unchangeable. This association suggests that when individuals are dissatisfied with a body part perceived as difficult to change, dysmorphic tendency is higher.

This study revealed that there is a relationship between Satisfaction with body parts and dysmorphic tendency. Moreover, considering each hypostatic factor, there was a difference in the relationship between dysmorphic tendency and the body part in question. Since there was a connection with Apprehension about others' evaluation of one's appearance and feelings about one's skin, the author suggests that introducing skin-care and makeup lessons within a therapeutic context might be effective in increasing self-esteem.

This was a cross-sectional study. Causal relationships were not shown (e.g., the body such as the period that cannot be satisfaction goes growing long become more dysmorphic tendency). In the future, the author would like to investigate additional aspects of the dysmorphic tendency. Multifaceted qualitative and longitudinal studies would help examine the specific impact of feelings about the body among Japanese females. 
Table 1 Intercorrelations Between All Variables.

\begin{tabular}{|c|c|c|c|c|c|c|c|c|}
\hline & & \multirow{2}{*}{$\begin{array}{l}\text { evaluation } \\
\text { apprehension of } \\
\text { appearance }\end{array}$} & \multirow{2}{*}{$\begin{array}{l}\text { obsessive } \\
\text { concentration on } \\
\text { appearance }\end{array}$} & \multicolumn{5}{|c|}{ body satisfaction } \\
\hline & & & & Body shape & Eyes & Skin & Nose and Mouth & Hair \\
\hline \multicolumn{2}{|c|}{ dysmorphic tendency } & $.899^{* *}$ & $.775^{* *}$ & $-.187^{* *}$ & $-.126^{*}$ & $-.179^{* *}$ & $-.214^{* *}$ & $-.117^{*}$ \\
\hline \multicolumn{2}{|c|}{ evaluation apprehension of appearance } & & $.419^{* *}$ & $-.158^{* *}$ & -.111 & $-.184^{* *}$ & $-.198^{* *}$ & -.099 \\
\hline \multicolumn{2}{|c|}{ obsessive concentration on appearance } & & & $-.160^{* *}$ & -.101 & -.105 & $-.158^{* *}$ & -.100 \\
\hline \multirow{4}{*}{ body satisfaction } & Body shape & & & & $.221^{* *}$ & $.487^{* *}$ & $.356^{* *}$ & $.322^{* *}$ \\
\hline & Eyes & & & & & $.459^{* *}$ & $.310^{* *}$ & $.225^{* *}$ \\
\hline & Skin & & & & & & $.524^{* *}$ & $.419^{* *}$ \\
\hline & Nose and Mouth & & & & & & & $.324^{* *}$ \\
\hline
\end{tabular}

${ }^{* *} p<.01,{ }^{*} p<.05$ 


\section{Notes}

(1) In previous research, the expressions "body dysmorphic disorder" and "dysmorphobia" have been used interchangeably. In this paper, the author used the unified term "dysmorphobia".

(2) The Body Cathexis Scale comprises 50 items. Because of restrictions on the number of questions that could be asked during the study, it was not possible to use all items. Therefore, the authors extracted 26 items, omitting those duplicated body parts.

(3) The Body Cathexis Scale includes relatively fewer items related to the face, therefore, these were added.

\section{References}

[1] Cabinet Office of Japan, (2009, March). A Summary Report of the Eighth World Youth Survey: VII. Outlook on Life (Publication of the Director-General for Policies on Cohesive Society). Accessed June 22, 2015. http://www8.cao.go.jp/youth/kenkyu/worldyouth8/html/ mokuji.html

[2] Cansever, A., Uzun, Ö., Dönmez, E., and Özşahin, A. 2003. "The Prevalence and Clinical Features of Body Dysmorphic Disorder in College Students: A Study in a Turkish Sample." Comprehensive Psychiatry 44: 60-4.

[3] Carroll, D. H., Scahill, L., and Phillips, K. A. 2002. "Current Concepts in Body Dysmorphic Disorder." Archives of Psychiatric Nursing 16: 72-9.

[4] American Psychiatric Association. 2013. Diagnostic and Statistical Manual of Mental Disorders (5th ed.). Washington, DC: Author.

[5] Eda, S. 2006. "Relationship between Body Image and
Dietary Habits of University Students." Bulletin of Kanto Gakuin University Society of Human and Environmental Studies 6: 41-50.

[6] Ishihara, H., and Ohsawa, K. 2003. "Young Women's Perception of Their Future Body Image and a View of Fashion." Bulletin of Nagoya Women's University Homemaking and Nature Editing Studies 49: 11-20.

[7] Masuda, Y., Ushida, S., and Nagano, M. 1992. "The Influence of the Estimation of Body Image upon Self-Consciousness (Part 1)." Journal of the Japan Research Association for Textile End-Use 33: 566-75.

[8] Nabeta, Y. 2011. Body Dysmorphic Disorder-Why would Obsessed with Beauty or Ugliness? Bunkyō, Tokyo: Kodansha.

[9] Ohmura, M., Kojima, Y., Nakata, Y., and Sawamiya, Y. 2015. "Development of Dysmorphobia Tendency Scale in Female Youth." Bulletin of Saitama Gakuen University. Japanese Journal of Applied Psychology 40 (3): 186-93.

[10] Ohmura, M., Kojima, Y., Nakata, Y., and Sawamiya, Y. 2014. "Fundamental Study on the Variability of the Body in University Students-Analysis of Free Descriptions about Variability by the KJ Method." Bulletin of Psychology Rissho University 5: 89-93.

[11] Ohmura, M., Kojima, Y., Nakata, Y., and Sawamiya, Y.2014. "Beautiful Skin Hide All Faults-Effects of Body Satisfaction on Self-esteem and Shyness in Japanese Female Youth."Psychology Research 5: 292-9.

[12] Phillips, K. A., Menarda, W., and Fay, C. 2006. "Gender Similarities and Differences in 200 Individuals with Body Dysmorphic Disorder." Comprehensive Psychiatry 47: 77-87.

[13] Tanaka, M., and Tayama, J. 2011. "Association between Body Dysmorphic Concern and Perfectionism Cognition among College Students." Japanese Journal of Cognitive Therapy 4: 140-8.

[14] Tutui, S. 2003. "Body Dysmorphic Disorder." Human Arts and Sciences 6: 139-50. 